\title{
Effects of Design Factors on Drag Forces and Deformations on Marine Aquaculture Cages: A Parametric Study Based on Numerical Simulations
}

\author{
Shuchuang Dong ${ }^{1, *}$, Xinxing You ${ }^{2} \mathbb{D}$ and Fuxiang $\mathrm{Hu}^{2}$ \\ 1 Institute of Industrial Science, The University of Tokyo, 5-1-5 Kashiwanoha, Kashiwa, Chiba 277-8574, Japan \\ 2 Graduate School of Marine Science and Technology, Tokyo University of Marine Science and Technology, \\ Minato, Tokyo 108-8477, Japan; yuukinsei@gmail.com (X.Y.); fuxiang@kaiyodai.ac.jp (F.H.) \\ * Correspondence: dongsc@iis.u-tokyo.ac.jp; Tel.: +81-47-7136-6967
}

Received: 16 January 2020; Accepted: 11 February 2020; Published: 16 February 2020

\begin{abstract}
In Japan, the marine aquaculture net cage has an important role in farming pacific bluefin tuna farming in oceans, and the design of the net cage needs to ensure robustness against hostile oceanic conditions. Accordingly, this study focuses on the drag forces and the cage volume of the net cage, and on their variations induced by different design parameters (netting solidity ratio, netting height, and bottom weight). A series of parametric studies on drag force and deformation of the net cage was conducted using a numerical simulation model. Accordingly, the contribution of each parameter to the drag and volume was analyzed using a generalized additive model. The results indicate that the bottom weight had the highest contribution to the holding ratio of the cage volume, whereas the netting height had the highest contribution to the drag coefficient of the net cage. Finally, a fast prediction model was created by a backpropagation (BP) neural network model and was examined for the accurate prediction of the objective variables.
\end{abstract}

Keywords: aquaculture net cage; drag force; net cage volume; generalized additive model; Backpropagation neural network

\section{Introduction}

In Japan, pacific bluefin tuna (Thunnus orientalis) farming has attracted attention as a promising business and has continued to grow [1]. The floating rope and HDPE (high-density polyethylene) floating collars net cage play important roles in farming tuna. Meanwhile, offshore fish farming with the use of the aquaculture net cage has been increasing owing to the problem of near-shore water pollution. However, strong ocean currents and waves make it easy to deform, and cause problems, such as damage and slow growth of pacific bluefin tuna. The development of optimum designs for open-sea net cages that can withstand adverse oceanic conditions is increasingly important.

The analyses of the deformations and drag forces of the net cages is the basis for the optimization of the design and safe use of the net cage system. At present, the hydrodynamic characteristics of similar net cages have been studied extensively with experimental methods. Fu et al. [2] conducted a model experiment to determine the cage volume and tension in the mooring line with the use of different mooring methods. Lader et al. [3] used a circular net cage made of nylon to clarify the drag force and volume by changing the bottom weight and current speed. Huang et al. [4-6] examined the volume change and the tension on the mooring line of the gravity-type net cage based on model testing. Klebert et al. [7] used pressure sensors to measure the three-dimensional deformation of full-scale cages in actual farming sea regions. Gansel et al. [8] measured the shape and drag of a full-scale net cage based on field tow testing. 
To reduce the optimization time of the net cage design, many researchers have also conducted numerical analyses of net cage systems. To our knowledge, several numerical methods have been proposed, which can be classified into two main approach types. One was based on Morison's equation in which the netting is modeled as truss or spring elements [9-12]. The other was based on screen force models, and the netting was modeled by consistent panels or screens [13]. The outcomes of these studies can provide valuable information necessary to the optimization design of the net cage so that it can withstand the intense hydrodynamic forces of ocean environments.

With the development of ICT (information and communication technology), a fast prediction model for predicting drag force and deformation of net cage is also required. Therefore, in this study, a numerical simulation model was proposed to determine the effects of different design parameters on the drag and shape changes of the net cage based on a finite element method, and a fast prediction model was created and examined. In addition, we also analyzed the contribution of the main parameters (netting solidity ratio, netting height, and bottom weight) to the drag and volume of the net cage.

\section{Materials and Methods}

\subsection{Net Cage Specifications}

The prototype net cage (Figure 1) used for farming pacific bluefin tuna was composed of floating collars, cylindrical side netting, bottom netting, and bottom weight (sinkers and sinker ropes). Detailed parameters of components of the prototype net cage are listed in Table 1. The cage has a circumference of $106 \mathrm{~m}$ and spans a distance of $12 \mathrm{~m}$ in the depth direction. The floating collar was constructed with high-density polyethylene pipe (HDPE), and the netting panel was made of polyethylene ultra-cross knotless netting (PEUC). The leaded lines and sinker ropes were placed on the bottom parts of the net to reduce deformation.

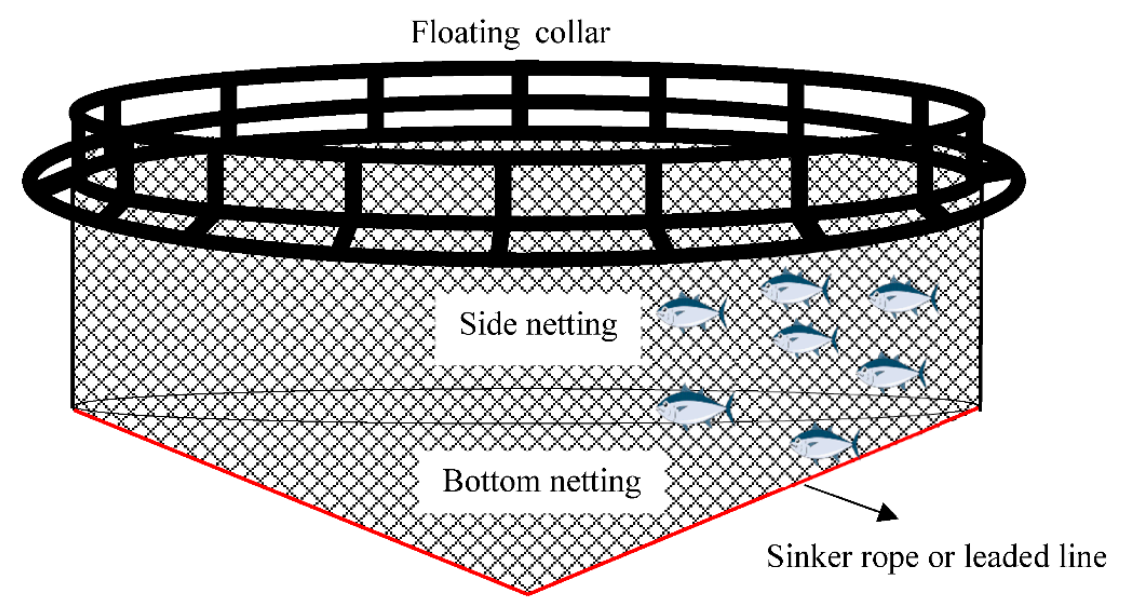

Figure 1. Schematic diagram of prototype net cage used for farming pacific bluefin tuna.

In the following numerical model verification experiment (Section 2.3), a scaled model of the net cage was employed. Based on Tauti's law [14], the model scales were: length scale $=1 / 28.3$, diameter scale $=1 / 5$, mesh size scale $=1 / 6.83$, velocity scale $=1 / 2.23$, force scale $=1 / 4004$. The specifications of the model net cage are listed in Table 1. 
Table 1. The Specifications of full-scale net cage and model net cage.

\begin{tabular}{cccc}
\hline Component & Parameter & Prototype Value & Model Value \\
\hline \multirow{3}{*}{ Floating pipe } & Material & High density polyethylene & High density polyethylene \\
& General diameter & $34.0 \mathrm{~m}$ & $1.2 \mathrm{~m}$ \\
& Pipe diameter & $35.5 \mathrm{~cm}$ & $1.5 \mathrm{~cm}$ \\
\hline \multirow{5}{*}{ Side netting } & Material & Polyethylene ultra cross knotless netting & Polypropylene knotless \\
& Net Height & $12.0 \mathrm{~m}$ & $0.42 \mathrm{~m}$ \\
& Twine diameter & $4.1 \mathrm{~mm}$ & $0.6 \mathrm{~mm}$ \\
& Mesh size & $100.0 \mathrm{~mm}$ & $20.0 \mathrm{~mm}$ \\
& Mesh type & Diamond mesh & Diamond mesh \\
\hline \multirow{3}{*}{ Bottom netting } & Material & Polyethylene knotless netting & Polypropylene knotless \\
& Twine diameter & $4.1 \mathrm{~mm}$ & $0.6 \mathrm{~mm}$ \\
& Mesh size & $75.0 \mathrm{~mm}$ & $20.0 \mathrm{~mm}$ \\
& Mesh type & Square mesh & Square mesh \\
\hline
\end{tabular}

\subsection{Numerical Simulations}

\subsubsection{Numerical Model}

Numerical simulations of the drag force and deformation of the net cage in uniform flow were conducted using a finite element method. In previous studies, the numerical procedure had been used to analyze the tension and shape of the fish netting system [15-18]. The mesh bar of the netting panel was modeled using a straight-line element with negligible bending and torsional stiffness (Figure 2). Netting panels can be considered as the components of such elements, which are connected with non-frictional hinges. The total potential energy of the $\Pi$ system can be expressed as,

$$
\Pi=-\sum_{i=1}^{f} F_{i} D_{i}+\sum_{g=1}^{m} T_{g}\left\{L_{g}\left(D_{i}\right)-L_{g 0}\right\}-\sum_{g=1}^{m} \frac{L_{g} 0}{2 E A_{g}} T_{g}{ }^{2}
$$

where $F_{i}$ is the equivalent nodal loading on the $i$-th node, $D_{i}$ is the nodal displacement of the element, $T_{g}$ is the axial force of the $g$-th element, $L_{g}$ is the initial length of the $g$-th element, $L_{g}$ is the length of the $g$-th element after deformation, $A_{g}$ is the cross-section area of the $g$-th element or mesh bar, $E$ is the Young's modulus of the material, $f$ is the nodal degree-of-freedom, and $m$ is the element number.

To determine the equilibrium shape of the unstable net cage system, the principle of minimum potential energy was applied. According to this principle, when the system is in an equilibrium state, the total potential energy becomes an absolute minimum, that is $\partial \Pi / \partial D_{i}=0$ and $\partial \Pi / \partial T_{g}=0$. The basic equations for the system can then be obtained as follows:

$$
\begin{gathered}
{\left[\begin{array}{ccccc}
\frac{\partial L_{1}}{\partial D_{1}} & \ldots \ldots & \ldots \ldots & \ldots \ldots & \frac{\partial L_{m}}{\partial D_{1}} \\
\cdot & & & & \cdot \\
\cdot & & & & \cdot \\
\frac{\partial L_{1}}{\partial D_{f}} & \ldots \ldots & \ldots \ldots & \ldots \ldots & \frac{\partial L_{m}}{\partial D_{f}}
\end{array}\right]\left[\begin{array}{c}
T_{1} \\
\cdot \\
\cdot \\
\cdot \\
\cdot \\
T_{m}
\end{array}\right]=\left[\begin{array}{c}
F_{1} \\
\cdot \\
\cdot \\
\cdot \\
\cdot \\
F_{f}
\end{array}\right]} \\
\quad\left\{L_{g}\left(D_{i}\right)-L_{g 0}\right\}-\frac{L_{g}}{E A_{g}} T_{g}=0 \quad g=1,2, \ldots, m
\end{gathered}
$$

The elements in the coefficient matrix in Equation (2) denote the direction cosines of the $g$-th element after deformation with respect to the X, Y, and Z-axes. Equation (3) shows the relationship between the element tension and nodal displacement. Consequently, it is clear that Equations (2) and (3) constitute the basic simultaneous equations for $(f+m)$ degrees-of-freedom with the nodal displacement 
$D_{i}$ and element tension $T_{g}$ being unknown parameters in the static response of the net cage. It is obvious that Equations (2) and (3) are nonlinear. To identify the numerical solution of the problem, the Newton-Raphson method was adopted.

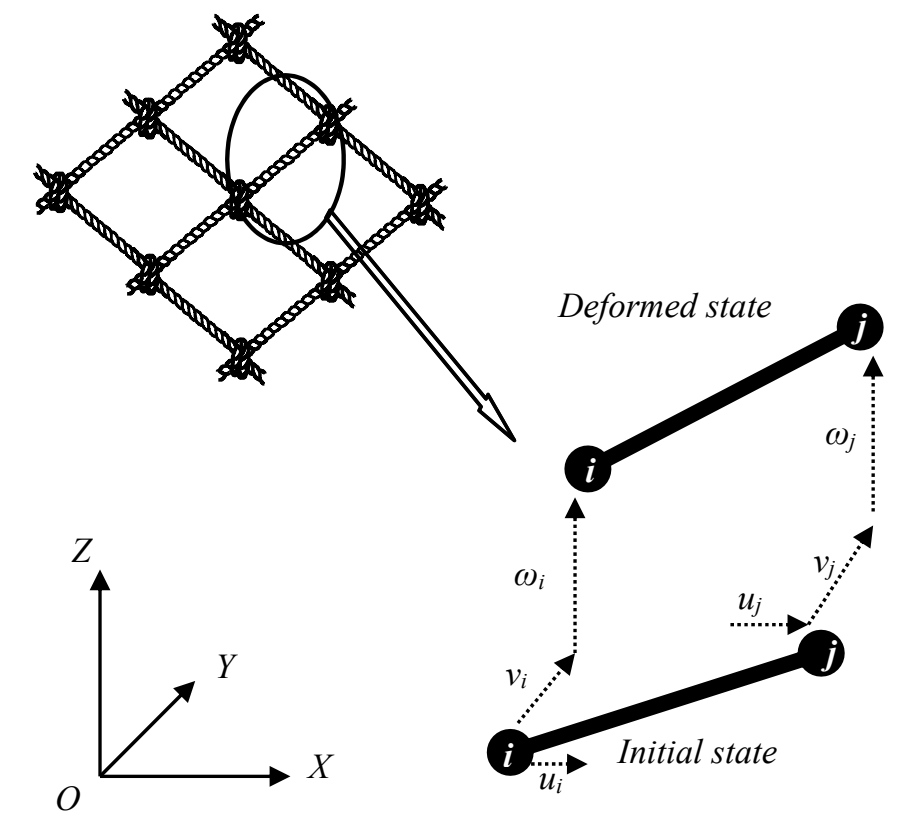

Figure 2. Diagram of the element motion. $X, Y$, and $Z$, are the global system coordinates; $u, v$, and $\omega$, denote the nodal displacements of an element in the direction of $X, Y$, and $Z$ axes; and $i$ and $j$ indicate the ends of the element, respectively.

\subsubsection{Hydrodynamic Loading Model}

The external forces $(F)$ in Equation (3) that act on each of the elements include the hydrodynamic force and gravity (weight and buoyancy). The hydrodynamic forces $\left(D_{x}, D_{y}\right.$, and $\left.D_{z}\right)$ can be expressed as:

$$
\begin{aligned}
D_{x} & =\frac{1}{2} \rho C_{x} d L U^{2} \\
D_{y} & =\frac{1}{2} \rho C_{y} d L U^{2} \\
D_{z} & =\frac{1}{2} \rho C_{z} d L U^{2}
\end{aligned}
$$

where $d$ is the diameter of the element, $L$ is the element length, $U$ is the relative velocity of the flow, and $\rho$ is the density of the fluid. When $l, m$, and $n$, are the direction cosines of the elements after deformation with respect to the $X, Y$, and $Z$ axes, respectively, the hydrodynamic forces coefficients $\left(C_{x}\right.$, $C_{y}$ and $C_{z}$ ) are expressed as:

$$
\begin{gathered}
C_{x}=C_{D 90}\left(1-l^{2}\right) \\
C_{y}=C_{D 90} \frac{l m^{2}}{\sqrt{\left(1-n^{2}\right)}} \\
C_{z}=C_{D 90} \frac{l^{2}}{\sqrt{\left(1-m^{2}\right)}}
\end{gathered}
$$

where $C_{D 90}$ is the normal drag coefficient for which the axis of the element is vertical to the flow. The normal drag coefficient $C_{D 90}$ was calculated as follows [19]:

$$
C_{D 90}=4.731 R^{-0.177}
$$

where $R e$ is the Reynolds number based on the diameter netting twines. 


\subsubsection{Parametric Study}

To evaluate the effects of the design parameters on the drag force and deformation of the net cage, a parametric study was constructed. Table 1 lists the detailed data of the original model scale net cage. In the side netting panel, there are 264 meshes in the circumference, 30 meshes in the depth direction, and 9568 meshes in the bottom netting. The total numbers of all the elements and nodes were 51,344 and 34,976 , respectively. If the number of degrees-of-freedom of the node is equal to three, the computer needs to have a huge capacity to create the stiffness matrix. Correspondingly, this cannot be achieved by a typical personal computer. Therefore, a mesh grouping method was applied to reduce the computational consumption and run time $[20,21]$. To obtain the volume of the net cage, the scalar triple method was used [4,22].

In addition, when the net cage is immersed in water, the upstream net reduces the water current inside the net cage, while it reduces the drag on the downstream net $[10,23,24]$. The current velocity acting on the downstream net $\left(U_{i n}\right)$ was obtained based on use of the following formulas:

$$
\begin{gathered}
U_{i n}=C_{r} U \\
C_{r}=1-0.46 C_{d}
\end{gathered}
$$

where $C_{r}$ is the ratio of the current velocity inside the net cage to the incident current velocity $(U)$, and $C_{d}$ is drag coefficient of netting. In this case, $C_{d}$ was proposed based on an empirical formula, as represented in our previous study [25].

In this study, the effects of net cage design parameters-netting solidity ratio $\alpha$, bottom weight $B w$, and netting height $H$-on the drag force and volume of the net cage were examined based on numerical simulations. The netting solidity ratio $\alpha$, was defined as the ratio of the projected area to the total area of the netting. In the case of diamond mesh with knotless, this solidity can be expressed as the following formula,

$$
\alpha=\frac{d(2-d / l)}{l \sin \theta}
$$

where $d$ is the twine diameter, $l$ is the bar length, and $\theta$ is the hanging angle and equal to $45^{\circ}$.

Table 2 shows the parameters used for the numerical simulations. The original values are shown in bold font, and a summary of the calculation process is listed below:

1. In the calculation that changed the value of $\alpha$, the current speed ranged from $10 \mathrm{~cm} / \mathrm{s}$ to $50 \mathrm{~cm} / \mathrm{s}$ at $10 \mathrm{~cm} / \mathrm{s}$ intervals. The value of $H$ was $0.42 \mathrm{~m}$, and the value of $B w$ was $476.5 \mathrm{~g}$

2. In the calculation that changed the value of $H$, the current speed ranged from $10 \mathrm{~cm} / \mathrm{s}$ to $50 \mathrm{~cm} / \mathrm{s}$ at $10 \mathrm{~cm} / \mathrm{s}$ intervals. The value of $\alpha$ was 0.12 and the value of $B w$ was $476.5 \mathrm{~g}$

3. In the calculation that changed the value of $B w$, the current speed ranged from $10 \mathrm{~cm} / \mathrm{s}$ to $50 \mathrm{~cm} / \mathrm{s}$ at $10 \mathrm{~cm} / \mathrm{s}$ intervals. The value of $\alpha$ was 0.12 and the value of $H$ was $0.42 \mathrm{~m}$.

Table 2. Design parameters of net cage varied in the numerical study.

\begin{tabular}{cccc}
\hline Current Speed $\boldsymbol{U} \mathbf{( \mathbf { c m } / \mathbf { s } )}$ & Netting Solidity $\boldsymbol{\alpha}$ & Netting Height $\boldsymbol{H}(\boldsymbol{m})$ & Bottom Weights $\boldsymbol{B w}(\mathrm{g})$ \\
\hline 10 & 0.06 & 0.33 & 226.5 \\
20 & 0.09 & $\mathbf{0 . 4 2}$ & 276.5 \\
30 & $\mathbf{0 . 1 2}$ & 0.51 & 326.5 \\
40 & 0.15 & 0.59 & 376.5 \\
50 & 0.18 & 0.67 & 426.5 \\
& 0.21 & 0.76 & $\mathbf{4 7 6 . 5}$ \\
& 0.24 & 0.84 & 526.5 \\
& 0.27 & 0.93 & 576.5 \\
& 0.3 & & 626.5 \\
& 0.34 & & 676.5 \\
& 0.38 & & 726.5 \\
& 0.42 & & \\
\hline
\end{tabular}




\subsection{Verification Experiment}

A numerical simulation generates outcomes at various conditions. Generated result can be examined from various perspectives. More important are the precisions of the calculations. To evaluate the precision of the numerical simulation, in this study, a series of model tests were performed in the flume tank at the Tokyo University of Marine Science and Technology. The observation section of the tank had a length of $9.0 \mathrm{~m}$, width of $2.2 \mathrm{~m}$, and a water depth of $1.6 \mathrm{~m}$. We used the original scaled net cage model which was described above. These drag forces and cage volume results were then compared with the numerical simulation results.

To conduct drag force measurements (Figure 3), we measured the drag force of the net cage with a small underwater load cell. The load cell had an accuracy of $3 \%$ of full scale, which was equal to $49.0 \mathrm{~N}$ according to the preliminary calibration. A propeller-type flowmeter was installed at a location of $\sim 1.5 \mathrm{~m}$ upstream of the model fish cage at the depth that matched the center of the model. The flow rate for the experiment was in the range of $5.0-50.0 \mathrm{~cm} / \mathrm{s}$ at $5 \mathrm{~cm} / \mathrm{s}$ intervals. The weights attached at the netting at the bottom part corresponded to $470.5 \mathrm{~g}$ in the experiment. The strain signals from load cell and flowmeter were transferred to the amplifier and then stored on a personal computer after digitization with the use of an $\mathrm{A} / \mathrm{D}$ converter. In the experiment, we used the mean of 400 data points obtained at $20 \mathrm{~Hz}$ in $20 \mathrm{~s}$ as the measurement value.

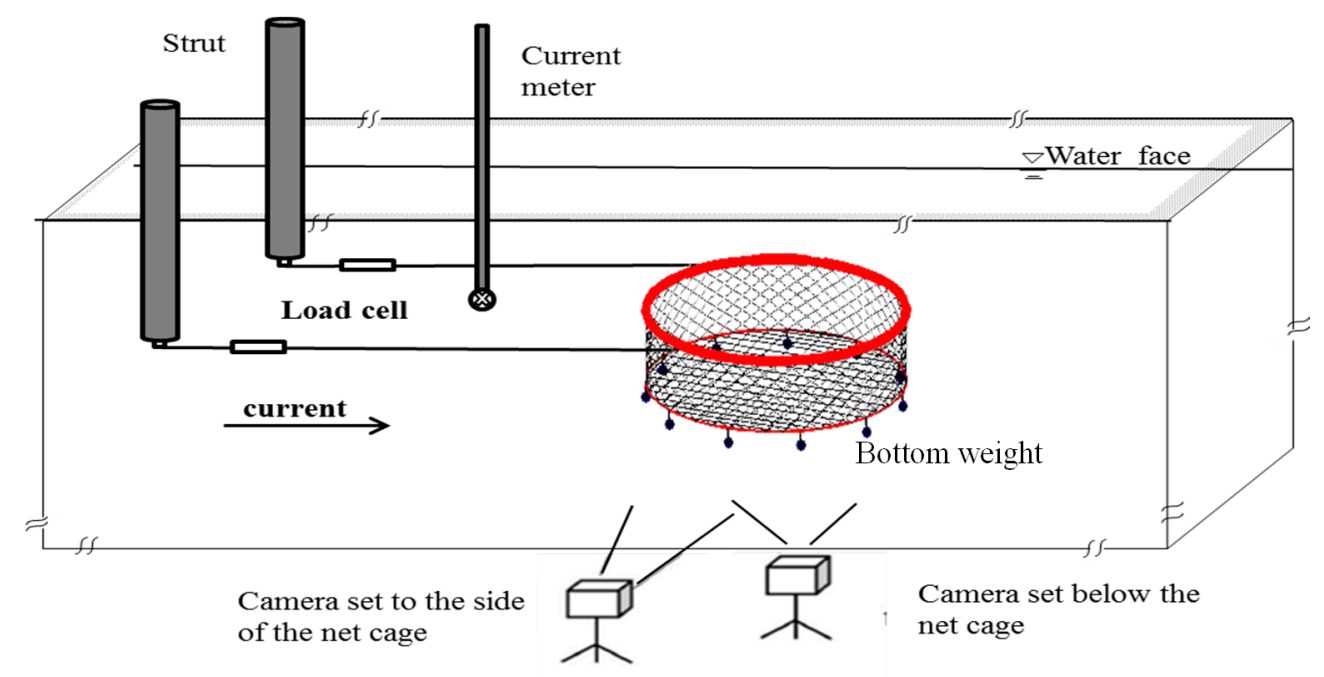

Figure 3. Schematic of experiment setup.

To measure deformation of the net cage, we imaged the shape of the model cage in a uniform flow with a flow rate in the range of $5-50 \mathrm{~cm} / \mathrm{s}$ at $5 \mathrm{~cm} / \mathrm{s}$ intervals from the side and below the water circulation tank observation port with two digital cameras (Figure 3). The three-dimensional coordinate values of the net cage were necessary to obtain the cage volume of the model net cage. We attached a small, lightweight, and waterproof light-emitting diode (LED) Milight $(4 \times 35 \mathrm{~mm}$, weight of $0.36 \mathrm{~g}$, Hiromi Sangyo Co., Ltd, Osaka, Japan) to the model net cage as a marker to track the deformation at different flow velocities. Figure 4 shows the locations of the small LED Milight. From the images captured by the two digital cameras, we read the three-dimensional coordinate values of the small LED Milight following binarization with the use of MATLAB (Version 2019a, Natick, MA, USA). We then interpolated according to the coordinates obtained above and calculated the volume based on use of the scalar triple method $[4,22]$. 


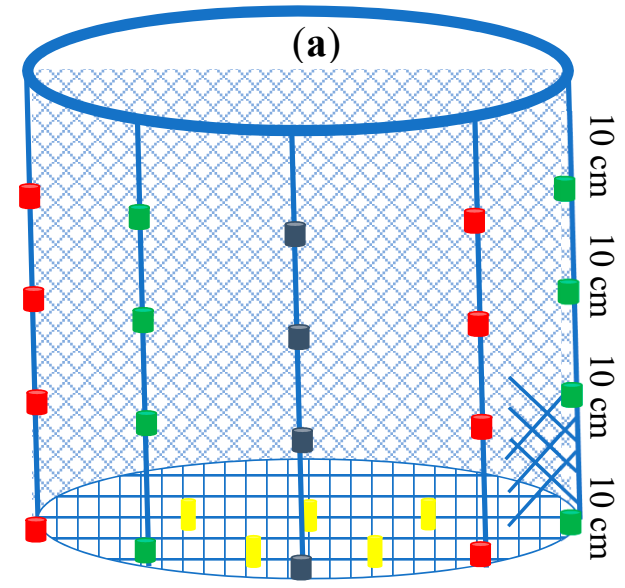

(b)

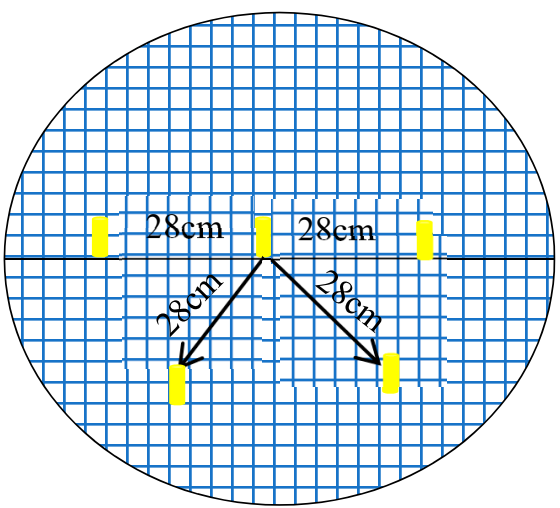

Figure 4. Placement of light-emitting diode (LED) markers on the side and bottom netting. (a) Side and (b) bottom nettings.

\subsection{Fast Prediction Model}

\subsubsection{Neural Network Model}

Backpropagation is an algorithm used to train a neural network in machine learning. Figure 5 shows the structure of the backpropagation neural network (BP neural network) [26]. In the figure, $X_{1}$, $X_{2}, \ldots, X_{n}$ are the input values for the input layer. $W_{i j}$ is the weight of the $j^{\text {th }}$ hidden layer from the $i^{i \text { th }}$ input layer, $W_{j k}$ is the weight of the $k^{\text {th }}$ output layer from the $j^{\text {th }}$ hidden layer, and $Y_{1}, Y_{2}, \ldots, Y_{m}$, is the output value of the BP neural network.

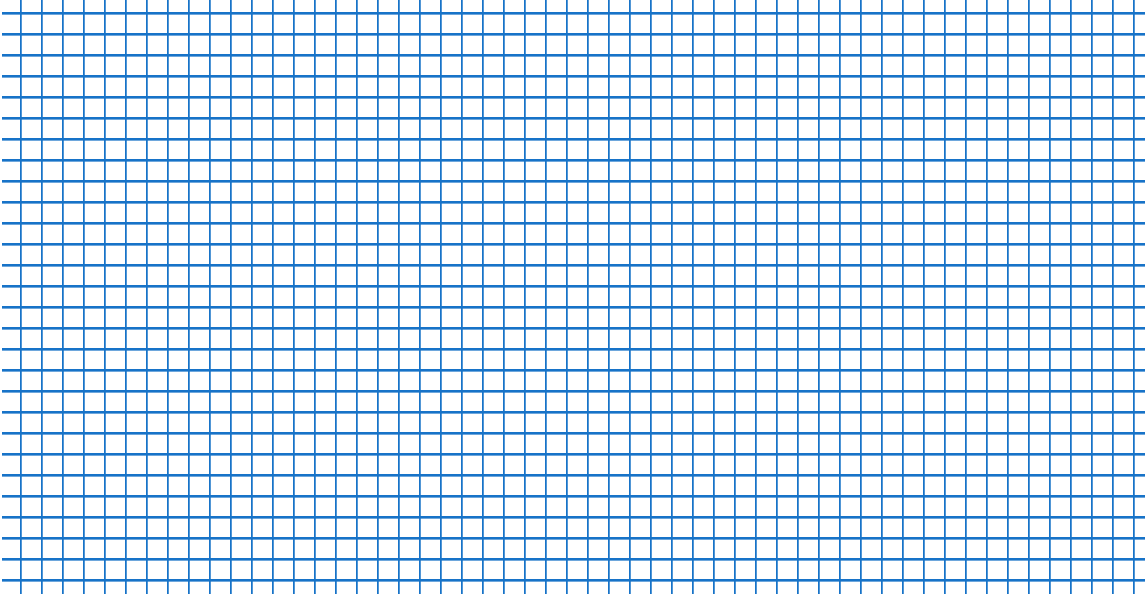

Figure 5. Topology diagram of backpropagation (BP) neural network.

We used MATLAB's Neural Network Toolbox to train the BP neural network. The number of units for the input and output layers were three and two, respectively, while the number of units for the hidden layer was 10. The maximum number of epochs was 500, the learning rate coefficient $\gamma$ was 0.1 , and the performance goal was $10^{-4}$ (mean squared error of predicted and desired values). To learn the weight of each layer, the trained function of the gradient descent backpropagation was used. For the transfer function from the input layer to the hidden layer, a tangent sigmoid transfer function (tansig) was selected, and for the transfer function from the hidden layer to the output layer, a linear transfer function (purelin) was chosen. 


\subsubsection{Training Data}

The parameters $\alpha, H / D$ (the netting height $H$ divided by the diameter of the net cage $D$ ), and $B w / B$ (the bottom weight $B w$ divided by the buoyancy $B$ of the pipe frame), were chosen as the explanatory variables. The objective variables used were the equivalent drag coefficient $K_{n}$ and volume holding ratio $C_{v}$ of the net cage. The $C_{v}$ and $K_{n}$ values are represented as follows.

$$
\begin{gathered}
C_{V}=\frac{V}{V_{0}} \\
K_{n}=\frac{R_{D}}{\rho A \alpha U^{2}}
\end{gathered}
$$

where $V$ is the net cage volume of the deformed net cage, $V_{0}$ is the volume of the cage in still water, $R_{D}$ is the drag force of the net cage, $A$ is the maximum cross-sectional area of the net cage, $\alpha$ is the netting solidity ratio, and $U$ is the current speed.

There were three design parameters with six patterns for each of these. This produces 216 combinations $(6 \times 6 \times 6=216)$. Given that the calculations required to analyze all these combinations with numerical simulations are considerable, combinations of the above design parameters were selected through an experimental design method based on an orthogonal array [27]. Subsequently, the drag forces and cage volume of the selected net cage model were obtained based on a numerical simulation model. These data were integrated with the data used for the parametric study. Table A1 shows the training data. With the use of a generalized additive model (GAM), we analyzed the contribution of each explanatory variable to the objective variables.

\section{Results}

Figure 6 shows the numerical results of the changes in the shape of the net cage obtained based on numerical simulations. These figures are side and top views and show the shape of the net cage when the current speed was 20,30, and $40 \mathrm{~cm} / \mathrm{s}$, when $\alpha$ was $0.12, H$ was $0.42 \mathrm{~m}$, and $B w$ was $476.5 \mathrm{~g}$.

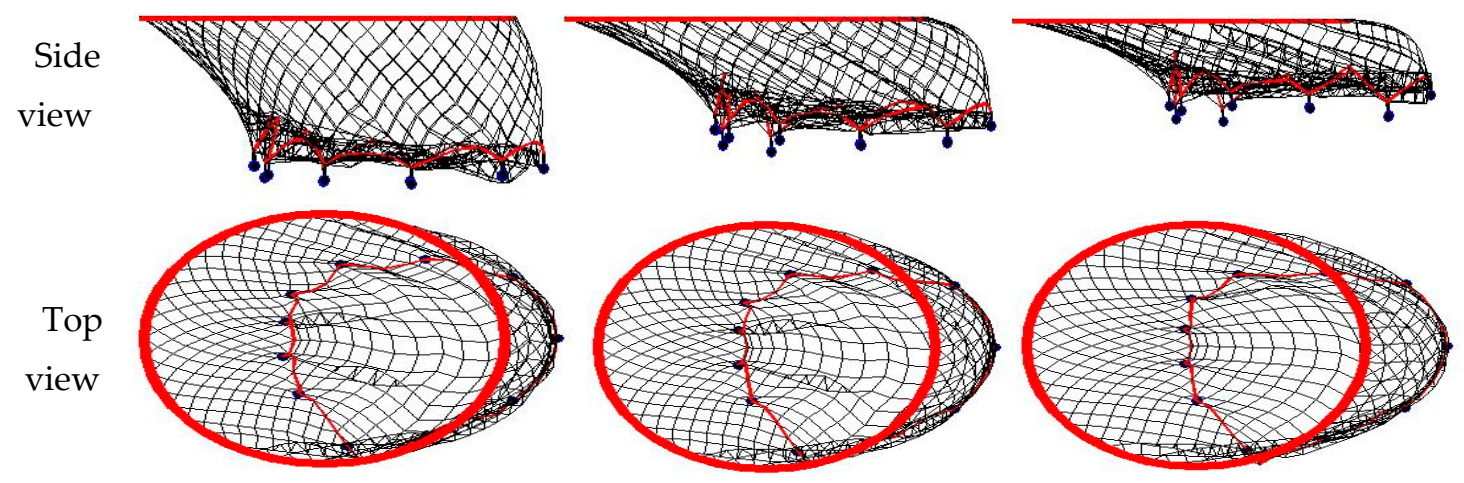

Figure 6. Equilibrium geometry of the net cage at current speeds of 20,30, and $40 \mathrm{~cm} / \mathrm{s}$.

\subsection{Effect of the Netting Solidity on Drag Force and Cage Volume}

Figures 7 and 8 show the effects of the netting solidity on the drag and cage volume. The starting point of the arrow in the figures indicates decreased values, and the end point indicates increased values. Figure 7 shows the effect of changing the value of $\alpha$ on $R_{D}$ of the net cage. The left subfigure shows the relationship between $R_{D}$ and $U$ for each $\alpha$, while the right subfigure shows the relationship between $R_{D}$ and $\alpha$ for each $U$. As the figure shows, for any $\alpha, R_{D}$ increases as $U$ increases. For $U$ values $\leq 20 \mathrm{~cm} / \mathrm{s}$, increases in the values of $R_{D}$ are proportional to the square of $U$. For $U$ values $\geq 20 \mathrm{~cm} / \mathrm{s}, R_{D}$ tends to increase in a linear fashion relative to $U$. This has a similar result to that described in [28], which is the reduction of the projected area caused by deformations. As shown in the right subfigure, when $\alpha$ increases, the drag also increases. This trend is clearer at higher $U$ values. At the maximum 
$U$ of $50 \mathrm{~cm} / \mathrm{s}$, the drag on the net cage for an $\alpha$ value of 0.46 was 3.77 times higher than that on the net cage with an $\alpha$ value of 0.06 . Similar to earlier simulation results [28], as the solidity increases, an approximately linear increase in drag forces was observed as a function of velocity.
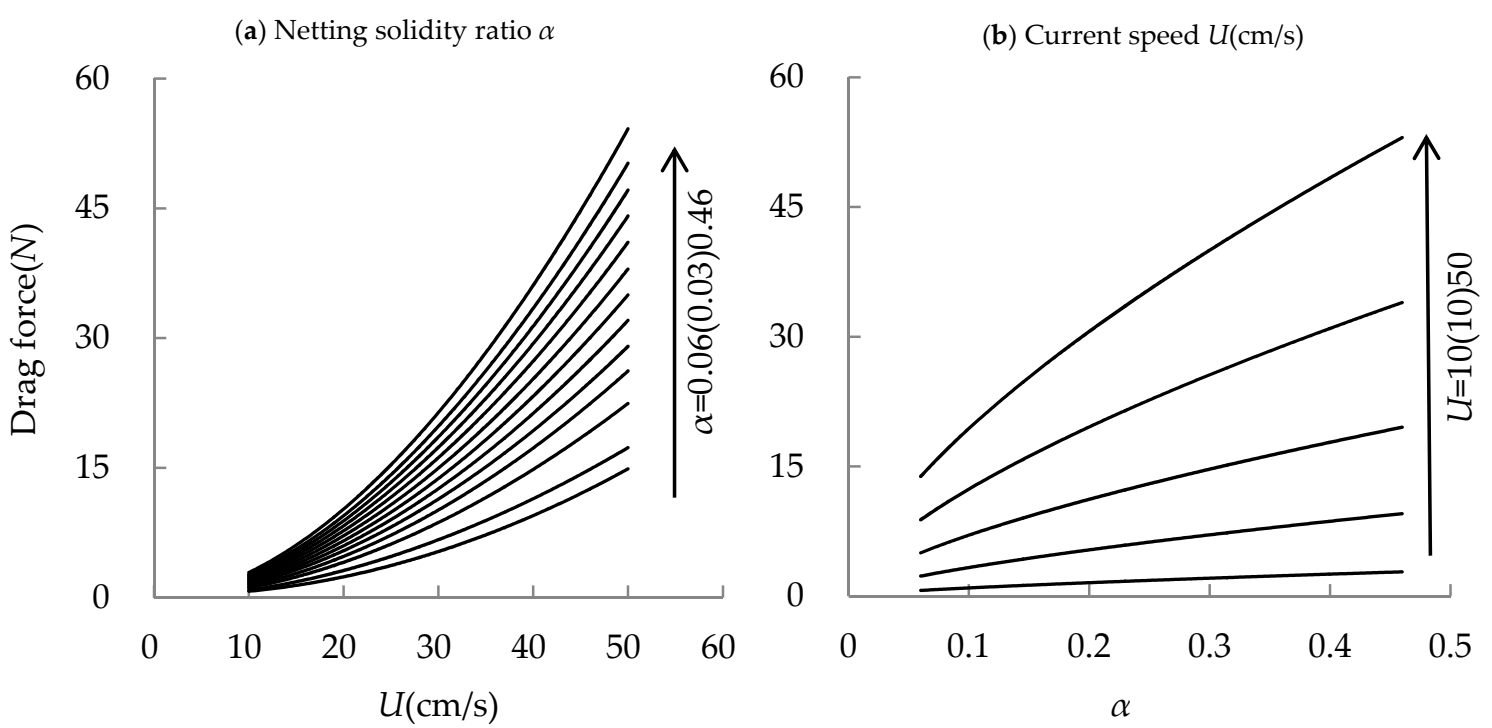

Figure 7. Relationship of drag force and mesh factor plotted against current speed. (a) the relationship of $R_{D}$ and $U$ for each $\alpha$; (b) the relationship between $R_{D}$ and $\alpha$ for each $U$.

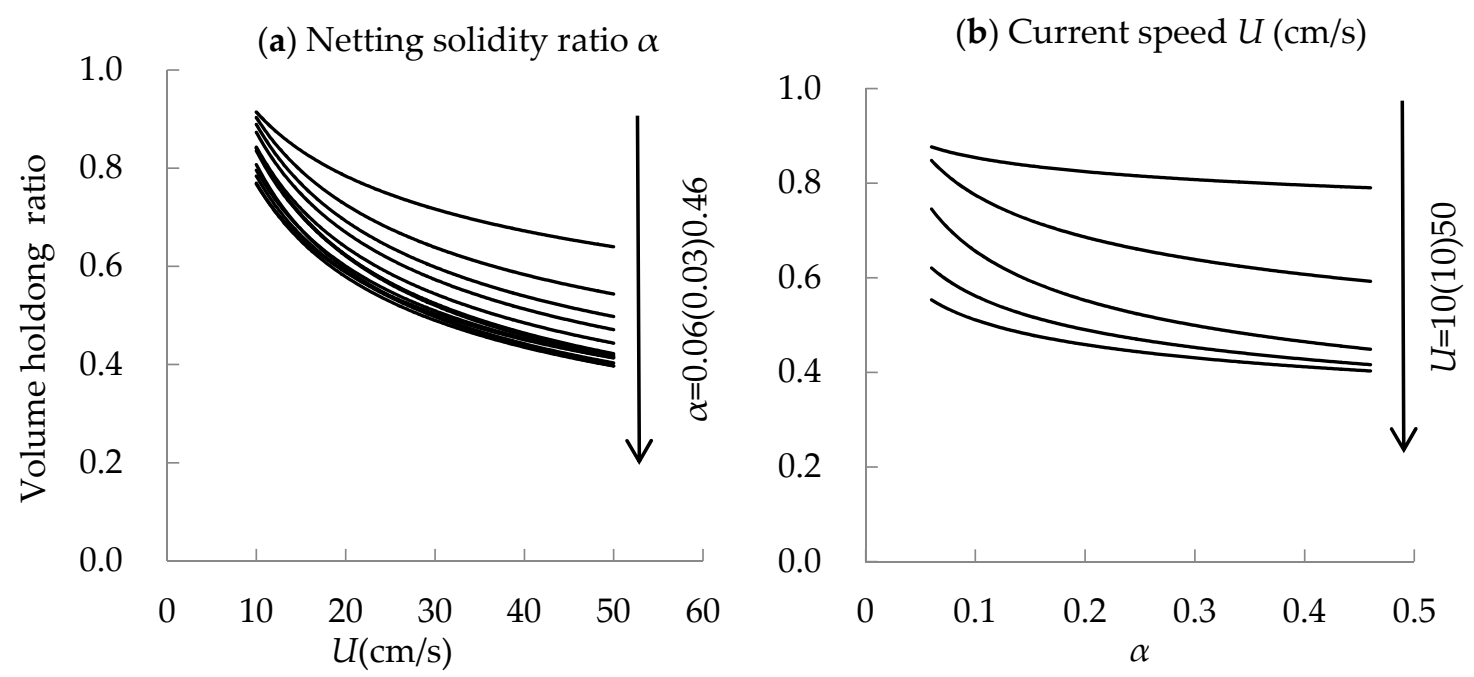

Figure 8. Relationship of volume holding ratio and mesh factor plotted against current speed. (a) the relationship of $C_{v}$ and $U$ for each $\alpha$; (b) the relationship between $C_{v}$ and $\alpha$ for each $U$.

Figure 8 shows the relationship between the netting solidity and the volume holding ratio of the net cage. As the figure shows, $C_{v}$ decreases as $U$ increases. At high-flow velocities, the rate of change of the trend was show, compared to fast decreasing rate at low-flow velocities. This may attribute to the fact that the deformation was large at high flow velocities, and to the fact that the net can be regarded as a solid body. At a high-current speed (e.g., $50 \mathrm{~cm} / \mathrm{s}$ ), the $C_{v}$ value for an $\alpha$ value of 0.46 was 0.42 . Compared to the net cage with an $\alpha$ value of 0.06 , the value of $C_{v}$ was 0.70 times smaller. As shown in the right subfigure, as $\alpha$ increases, $C_{v}$ decreases. When the value of $\alpha$ exceeds 0.3 for each current speed, the value of $C_{v}$ becomes constant at all velocities. 


\subsection{Effect of the Netting Height on the Drag Force and Cage Volume}

Figure 9 shows the effect of the netting height on the drag of the net cage, and Figure 10 shows the effect on the volume holding ratio of the net cage. As shown in Figure 9, the drag forces on the net cage increases at increasing current speeds. As $H$ increases, $R_{D}$ also increases. As shown by the right subfigure, when the value of $U$ is low, the value of $R_{D}$ increases linearly as $H$ increases. However, when the value of $U$ is high, the increase in the drag force becomes prominent. At the maximum current speed of $50 \mathrm{~cm} / \mathrm{s}$, the drag force of the net cage with a netting height of $93 \mathrm{~cm}$ increases by 1.43 times compared to its value in the case at which the netting height is $33 \mathrm{~cm}$. In addition, the trend of the drag forces and netting height yielded similar results to the netting solidity.
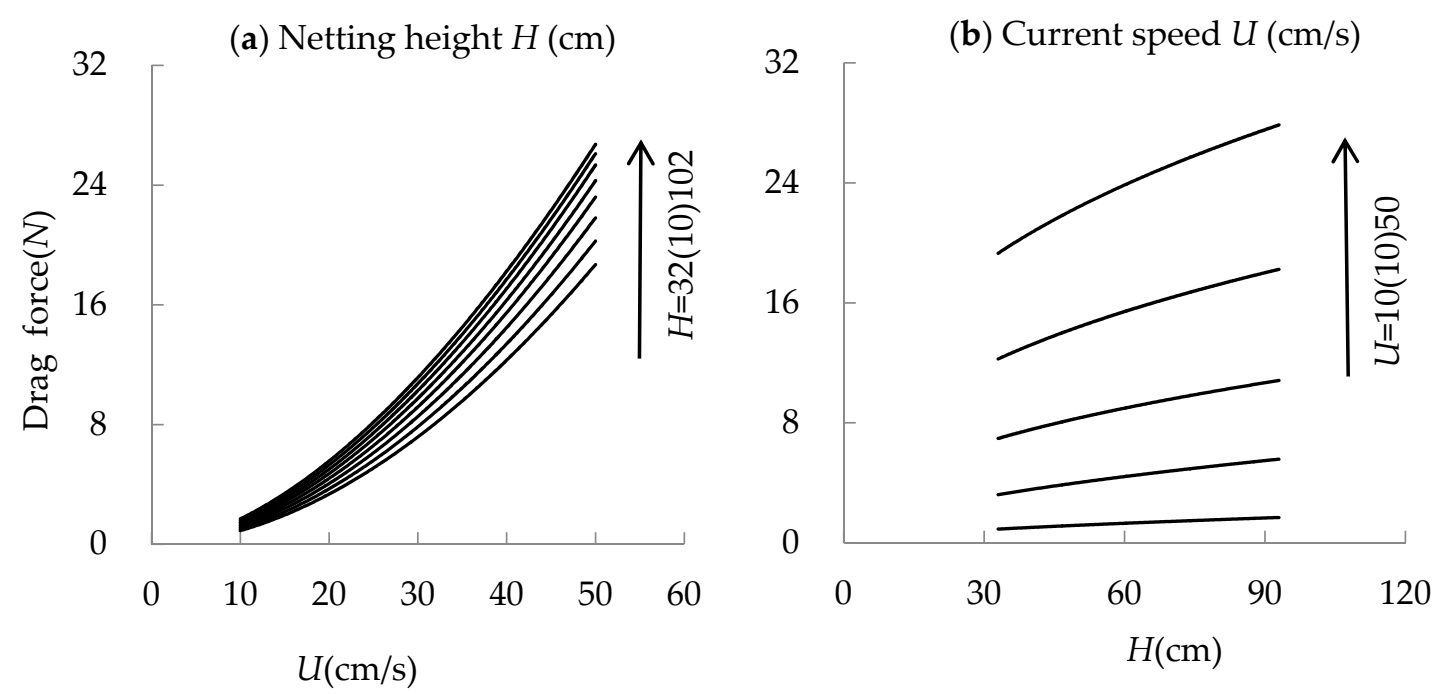

Figure 9. Relationship of drag force and net depth plotted against current speed. (a) the relationship of $R_{D}$ and $U$ for each $H$; (b) the relationship between $R_{D}$ and $H$ for each $U$.

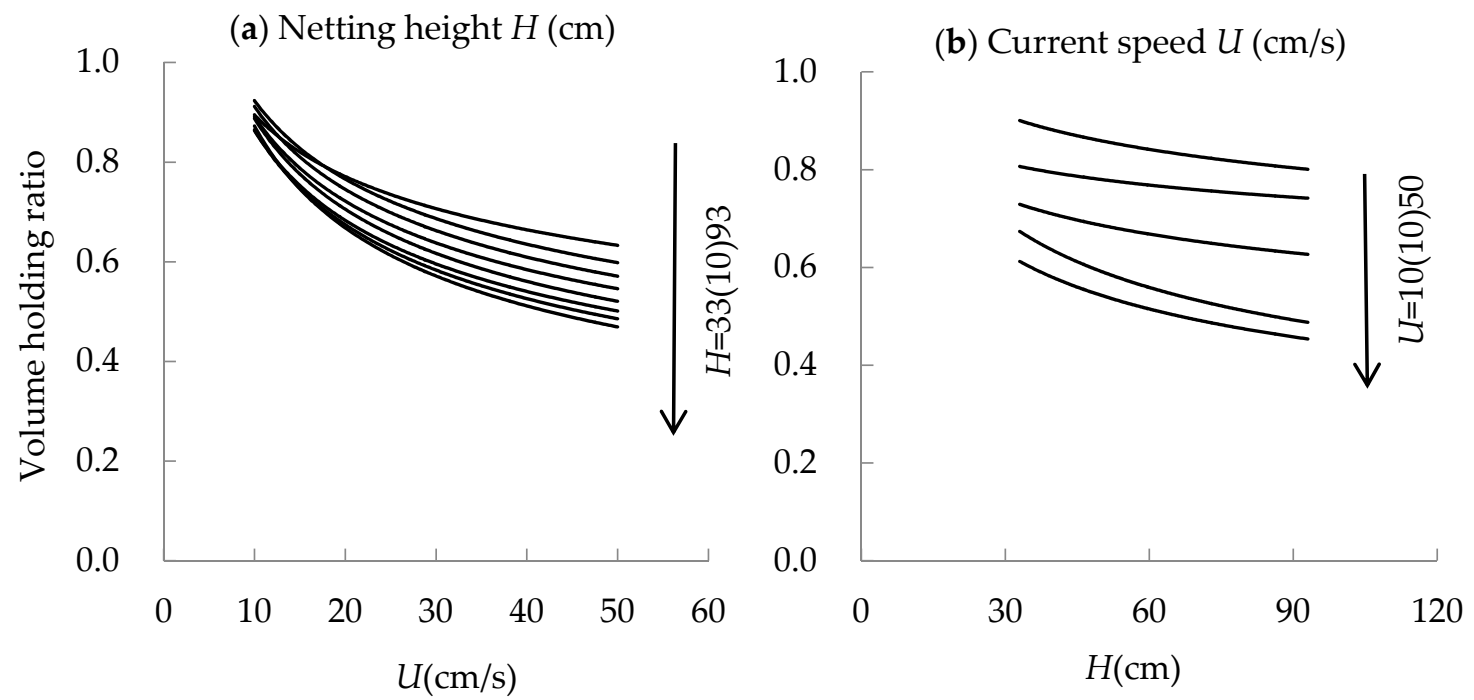

Figure 10. Relationship of volume holding ratio and net depth plotted against current speed. (a) the relationship of $C_{v}$ and $U$ for each $H$; (b) the relationship between $C_{v}$ and $H$ for each $U$.

Figure 10 shows that the volume holding ratio increases as the current speed increases. At each current speed, $C_{v}$ decreases as $H$ increases. At high current speeds, this decreasing trend becomes prominent. At the maximum current speed of $50 \mathrm{~cm} / \mathrm{s}$, the $C_{v}$ of the net cage with $H$ of $93 \mathrm{~cm}$ was 0.78 times smaller compared to the case where $H$ was $33 \mathrm{~cm}$. As $H$ increases, the decrease in $C_{v}$ becomes prominent as the current speed increases. Similar to the change trend of drag force and net height, 
the relationship between cage volume and net height is similar to the relationship between volume and netting solidity.

\subsection{Effect of Bottom Weight on the Drag Force and Cage Volume}

Figure 11 shows the effect of the bottom weight on the drag force of the net cage. As the figure shows, the drag force increases as the current speed increases. At a lower current speed, the value of $R_{D}$ on net cage barely changes as $B w$ increases, and reaches a constant value. At higher current speeds, $R_{D}$ increases as $B w$ increases. At the maximum current speed of $50 \mathrm{~cm} / \mathrm{s}$, the $R_{D}$ value on the net cage with a $B w$ of $726.5 \mathrm{~g}$ is 1.10 times higher compared to the case at which the $B w$ value is $226.5 \mathrm{~g}$.

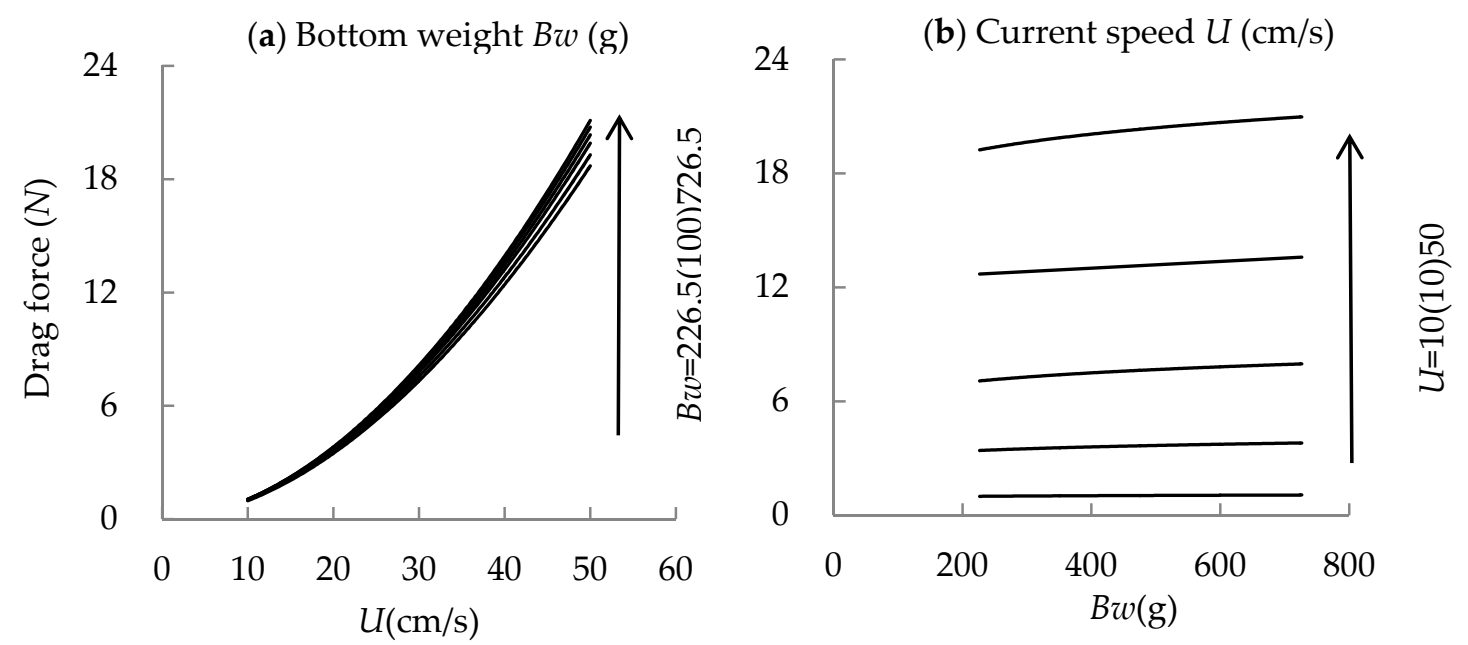

Figure 11. Relationship of drag force and bottom weight plotted against current speed. (a) the relationship of $R_{D}$ and $U$ for each $B w$; (b) the relationship between $R_{D}$ and $B w$ for each $U$.

Figure 12 shows the effect of the bottom weight on the volume holding ratio of the net cage. The same figure shows that as the current speed increases, the $C_{v}$ of the net cage decreases. For all the current speeds, as $B w$ increases, $C_{v}$ increases. At the maximum current speed of $50 \mathrm{~cm} / \mathrm{s}$, the $C_{v}$ value of the net cage with a $B w$ value of $726.5 \mathrm{~g}$ is 1.22 times higher than its value in the case at which $B w$ is $226.5 \mathrm{~g}$. Overall, there is not a significant correlation between the drag force and bottom weight. Additionally, a negative correlation was observed between drag force and cage volume for any bottom weights was (similar to [28]).
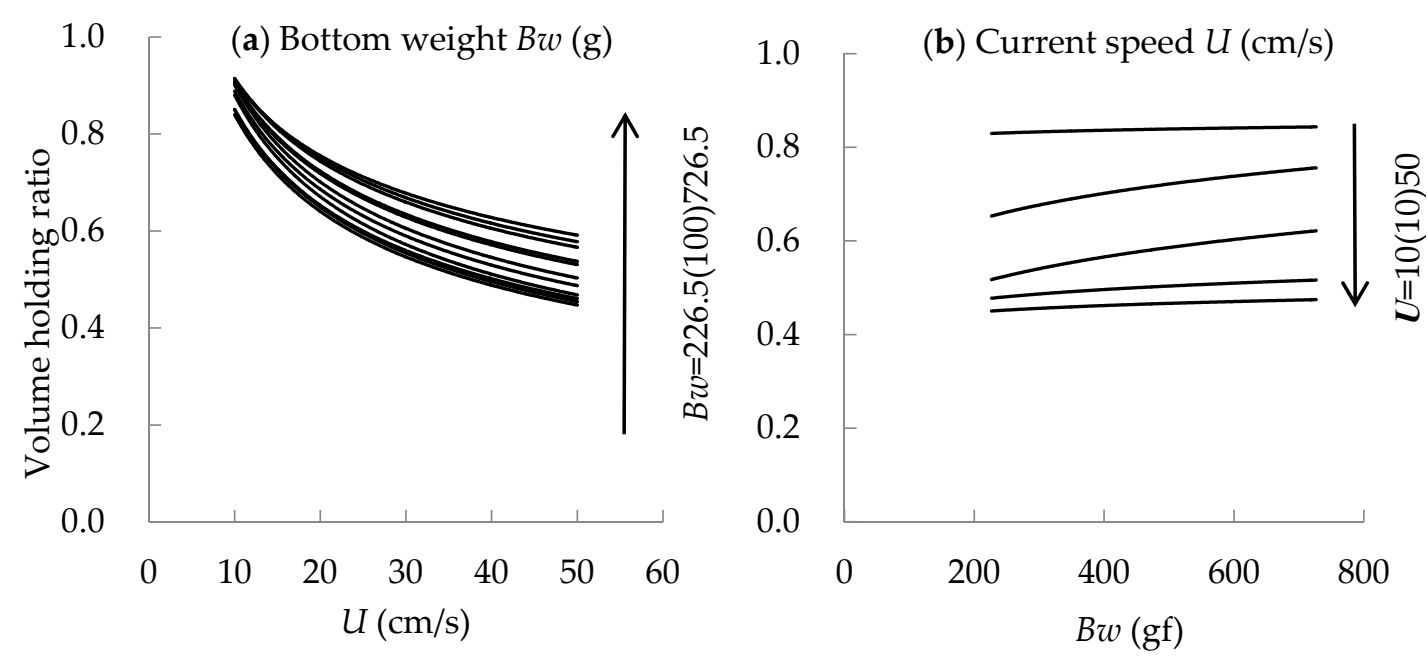

Figure 12. Relationship of volume holding ratio and bottom weight plotted against current speed. (a) the relationship of $C_{v}$ and $U$ for each $B w$; (b) the relationship between $C_{v}$ and $B w$ for each $U$. 


\subsection{Contributions of Explanatory Variables}

We examined the relationship between each explanatory variable and objective variable using GAM analyses (Figures 13 and 14). Figure 13 shows the relationships of each explanatory variable with the drag coefficient of the net cage. The figure shows that as $\alpha$ and the $H / D$ increase, the $K_{\mathrm{n}}$ of the net cage decreases. When the $B w / B$ increases, the value $K_{n}$ of the net cage increases. Conversely, the $C_{V}$ of the net cage decreases slightly as $\alpha$ increases. Additionally, as the $H / D$ and the $B w / B$ increase, the $C_{V}$ of the net cage increases slightly (Figure 14).

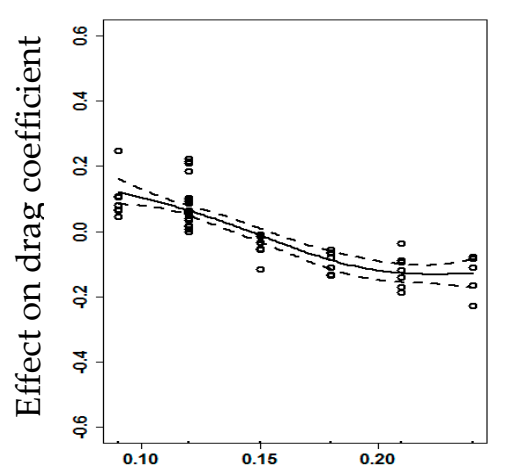

(a) Netting solidity ratio $\alpha$

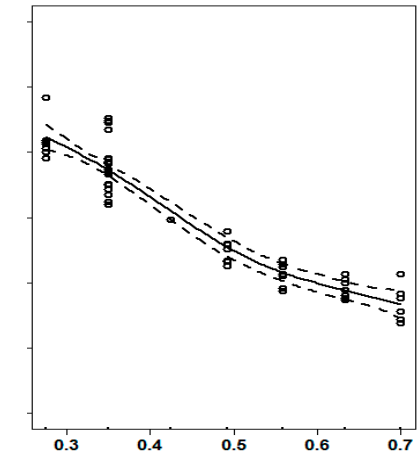

(b) Net Height/Net Diameter (H/D)

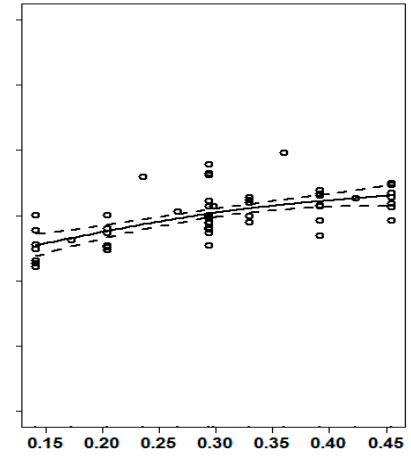

(c) Bottom weight/Buoyancy $(B w / B)$

Figure 13. The relationship between design factors and drag coefficient on the generalized additive (GAM) model. (The y-axis represents the partial effect of each variable; Dashed lines indicate 95\% confidence bounds; Solid lines are smooth curves).

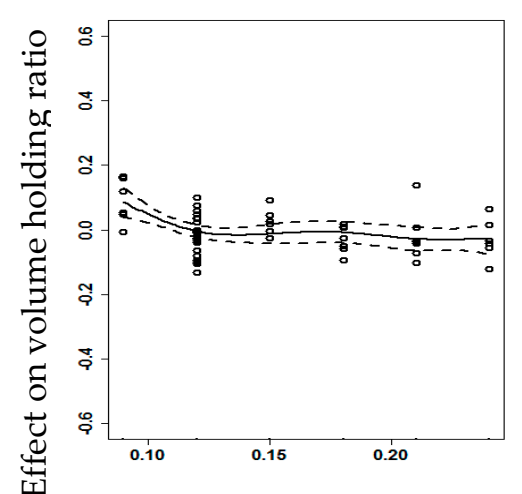

(a) Netting solidity ratio $\alpha$

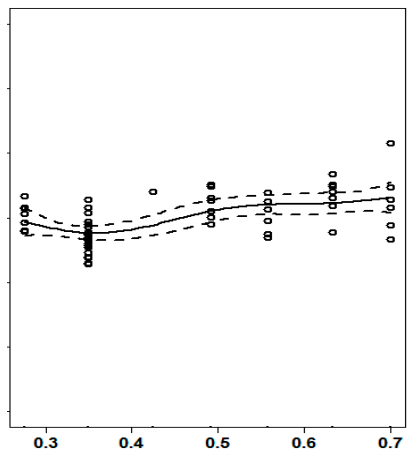

(b) Net Height/Net Diameter (H/D)

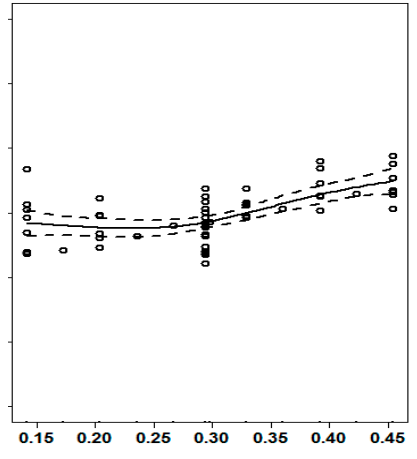

(c) Bottom weight/Buoyancy $(B w / B)$

Figure 14. Relationships between design factors and volume holding ratio in the case of the GAM model. (The y-axis represents the partial effect of each variable; Dashed lines indicate $95 \%$ confidence bounds; Solid lines are smooth curves).

The equivalent drag coefficient $K_{\mathrm{n}}$ and cage volume holding ratio $C_{V}$ obtained based on the GAM analyses are listed in Tables 3 and 4 , respectively. For both the $K_{\mathrm{n}}$ and $C_{V}$ of the net cage, the $p$ values of all the explanatory variables were 0.05 or less, which demonstrated statistical significance. Based on the F-test, the bottom weight had a maximum contribution to the cage volume holding ratio, followed by $H / D$ and $\alpha$. H/D had the highest contribution to the drag coefficient of the net cage, followed by $\alpha$ and $B w / B$. 
Table 3. Statistical results of GAM analysis for volume holding ratio.

\begin{tabular}{cccc}
\hline Model Factors & EDF & F-Value & $p$-Value \\
\hline Netting solidity ratio $\alpha$ & 3.32 & 3.68 & 0.008199 \\
Netting height/Diameter of net cage $(H / D)$ & 3.28 & 5.94 & 0.000625 \\
Bottom weight/Buoyancy $(B w / B)$ & 2.65 & 10.30 & $<1.3 \times 10^{-5}$ \\
\hline
\end{tabular}

Table 4. Statistical results of GAM analysis for equivalent drag coefficient.

\begin{tabular}{cccc}
\hline Model Factors & EDF & F-Value & $p$-Value \\
\hline Netting solidity ratio $\alpha$ & 2.63 & 40.73 & $<2.8 \times 10^{-16}$ \\
Netting height/Diameter of net cage $(H / D)$ & 2.90 & 139.79 & $<2.0 \times 10^{-16}$ \\
Bottom weight/Buoyancy $(B w / B)$ & 1.71 & 16.00 & $<2.7 \times 10^{-6}$ \\
\hline
\end{tabular}

\section{Discussion}

\subsection{Precision of the Numerical Simulation Model}

Figure 15 shows an example of the comparison between the experimental photographs from the model net cage with the simulated shapes. These figures were obtained based on simulations when the current speed was 20,30, and $40 \mathrm{~cm} / \mathrm{s}$. As shown in the comparison of the shapes in Figure 15, the shapes of the net cage at each current speed were consistent between the analytical and experimental shapes.

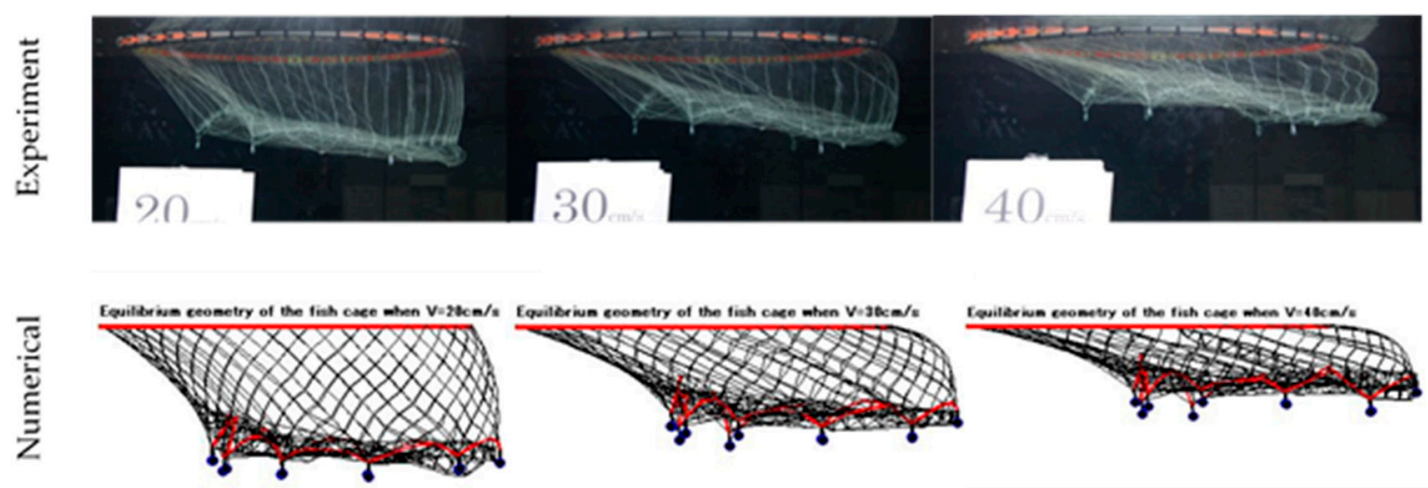

Figure 15. Snapshots from experimental and numerical simulations.

Figure 16 shows the comparison between the experimental results for the drag and volume measured in the model experiment with the simulation results. The experimental and calculated results were consistent for the drag and volume of the net cage when the current speed was low $(\leq 15 \mathrm{~cm} / \mathrm{s})$. However, when the current speed increased, some differences were noted. Overall, the numerical simulations reproduced the experimental results relatively well, and the mean relative errors were $13.3 \%$ and $9.1 \%$ for the drag and volume, respectively. 

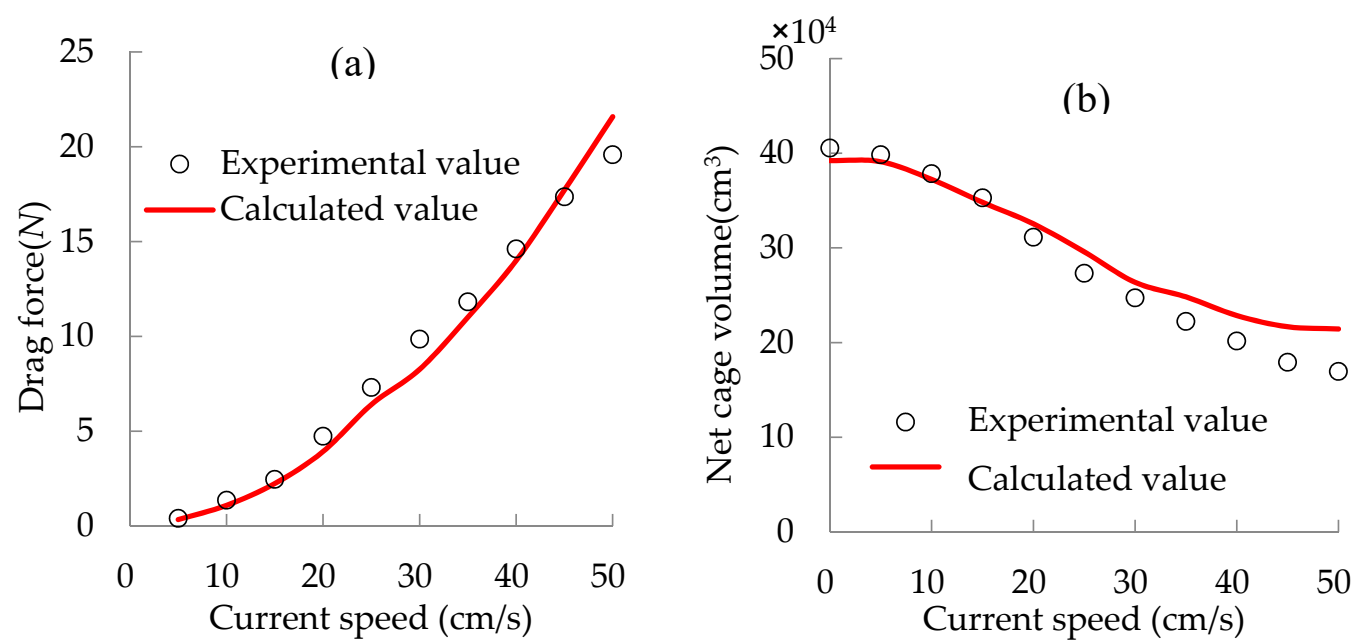

Figure 16. Comparison of drag force and cage volume between the experimental and simulation results as a function of current speed $(\alpha=0.12, H=0.42 \mathrm{~m}, B w=476.5 \mathrm{~g})$. (a) the drag force; (b) the cage volume.

\subsection{Precision of the Neural Network}

Figure A1 shows the created BP neural network model. Tables 5 and 6 show the weights of all the layers. To evaluate the precision of the BP neural network model in Figure A1, the calculated results of the numerical simulation model and the predicted value from the BP neural network model are plotted in Figure 17. The regression formula of the numerically calculated results and predicted values were obtained, and the coefficient of determination $R^{2}$ was calculated based on a regression fitting. The graph shows that there were no outliers from $\mathrm{y}=\mathrm{x}$, and $R^{2}$ was almost equal to one. Additionally, it was shown that the created BP neural network model predicts the response variables accurately.

Table 5. Weights $W_{i j}$ from the $i$ th input layer to $j$ th hidden layer.

\begin{tabular}{|c|c|c|c|c|c|c|}
\hline$i^{j}$ & 2 & 4 & 6 & 8 & 9 & 10 \\
\hline 1 & 1.9708271 .107892 & -1.745191 .920279 & $-0.05492-2.02666$ & -1.566210 .207186 & 2.664381 & 2.094821 \\
\hline 2 & -2.021041 .847165 & $1.984459-0.27105$ & $2.026001-1.78069$ & -1.102832 .415709 & 1.12061 & 2.399915 \\
\hline 3 & $1.114336-2.07818$ & 1.1448792 .364004 & $1.274584 \quad 1.44558$ & $2.177577-0.59733$ & 1.148622 & -1.16935 \\
\hline
\end{tabular}

Table 6. Weights $W_{j k}$ from the $j$ th hidden layer to $k$ th output layer.

\begin{tabular}{|c|c|c|c|c|c|c|}
\hline$k^{j}$ & 1 & 2 & 4 & 5 & 7 & 10 \\
\hline 1 & -0.5315 & 0.275588 & $-0.12305-0.04154$ & $0.305313-0.41142$ & $1.005371-0.83501$ & -0.324280 .95714 \\
\hline 2 & 0.06715 & -0.18221 & $-0.00363-0.02391$ & -0.190820 .163327 & $-0.00961-0.04366$ & $-0.00862-0.44308$ \\
\hline
\end{tabular}



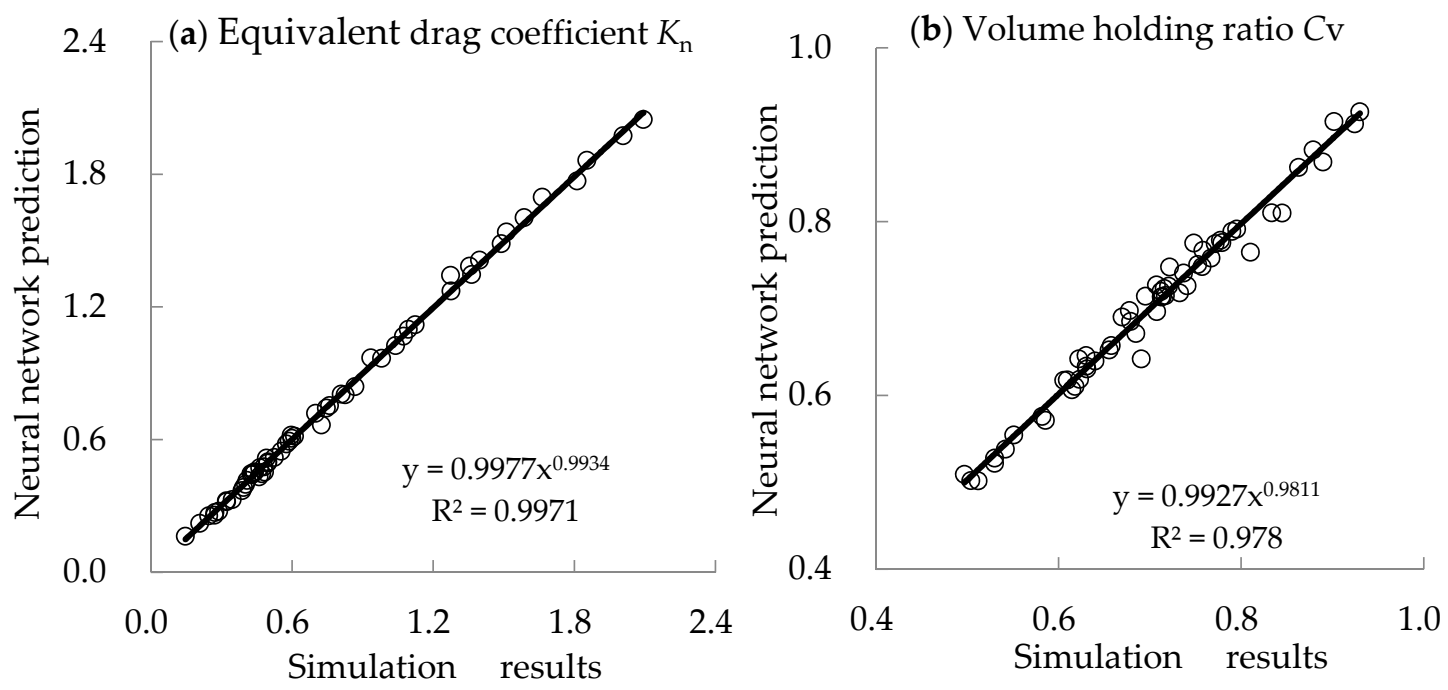

Figure 17. Relationships between neural network prediction and simulated results. (a) Equivalent drag coefficient; (b) Volume holding ratio

\subsection{Optimized Net Cage Model}

The results listed above confirm the effectiveness of the proposed fast prediction model. However, a net cage system that is under a repetitive load, such as the load imposed by waves, needs to be considered, and a fatigue analysis needs to be performed. In the future, the fatigue damages to the net cage frame and mooring line in the presence of waves need to be confirmed and integrated with the fast prediction model to optimize the net cage design in actual sea regions.

\subsection{Scale Effect}

Neither Tauti's law nor Froude's law lead to perfect physical analogies. For this reason, the smaller the scale ratio is, the larger the actual conversion value obtained from model experiments. Accordingly, numerical calculations will generate a large error, and the problem of the so-called scale effect cannot be ignored [29,30]. In the case of this study, the Reynolds number was defined as follows,

$$
R_{d}=\frac{U d}{\mu}
$$

where $\mu=0.01 \mathrm{~cm}^{2} / \mathrm{s}$ is the dynamic viscosity of water, and the diameter of twine $d$ was considered equal to the characteristic length of netting.

In the validation experiment described above, the current velocity range was $5.0-50.0 \mathrm{~cm} / \mathrm{s}$, and the $R_{d}$ was in the range of 30-300. Based on Tauti's law, in the full-scale net cage, the current velocity conversion was in the range of $11.15-111.5 \mathrm{~cm} / \mathrm{s}$. For a full-scale twine diameter of $0.41 \mathrm{~cm}$, the $R_{d}$ would take values in the range of 457-4570. According to the relationship between the drag coefficient and the Reynolds number, a large deviation is expected to occur in the calculation of drag forces.

To achieve a more accurate conversion between the model and full-scale net cage, the model should either be made as large as possible, or the similarity law needs to be further improved (Hu et al. [29]). In addition, the behaviors of the net cage under the wave and wave combined current conditions must be considered.

\section{Conclusions}

In this study, we employed the finite element method to construct a numerical model for net cages. A series of parametric studies were conducted to evaluate the effects of the design parameters (netting solidity ratio $\alpha$, netting height $H$, and bottom weight $B_{w}$ ) on the drag force and deformation of the net 
cage. A validation experiment was also performed to evaluate numerical model, and good agreement was demonstrated.

The contribution of each design parameter to the drag force and volume was analyzed using a generalized additive model. The bottom weight had the highest contribution to the cage volume, whereas the netting height had the highest contribution to the drag force of the net cage.

A BP neural network model was created to predict the drag force and cage volume. As indicated, a good comparison to simulation results was confirmed.

The scale effect between of the model and full-scale net cage was also discussed.

Author Contributions: Conceptualization, S.D. and F.H.; methodology, S.D. and X.Y.; formal analysis, S.D. and X.Y.; writing-Original draft preparation, S.D.; writing-Review and editing, X.Y. and F.H. All authors have read and agreed to the published version of the manuscript.

Funding: This research received no external funding.

Acknowledgments: The authors would like to thank the reviewers for their constructive comments and suggestions.

Conflicts of Interest: The authors declare no conflict of interest.

\section{Appendix A}

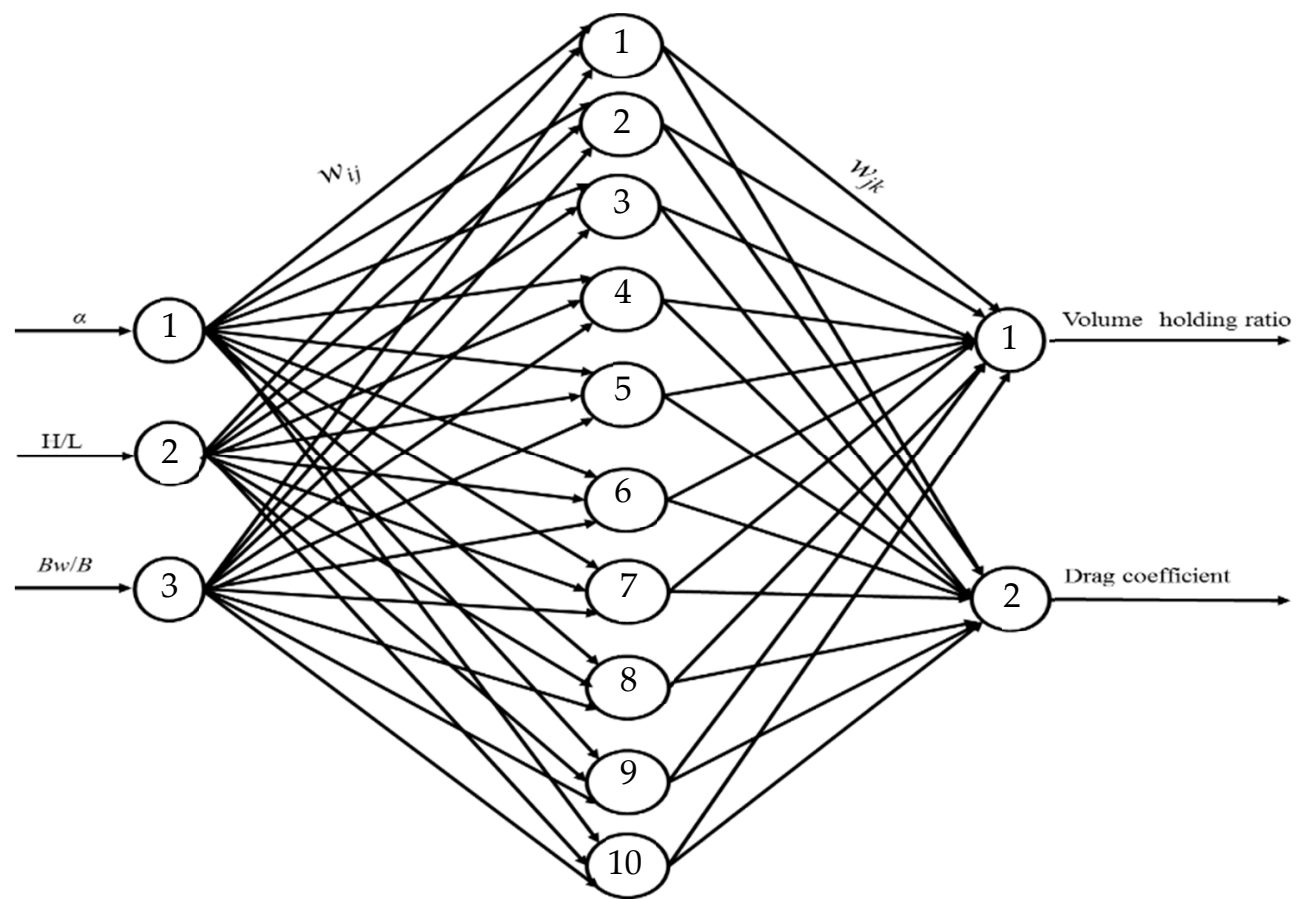

Input layer Hidden layer $\quad$ Output layer

Figure A1. Constructed BP neural network. 
Table A1. Data used to train the neural network.

\begin{tabular}{|c|c|c|c|c|c|}
\hline No. & Mesh Factor $\alpha$ & $\begin{array}{l}\text { Height/Diameter } \\
\text { of Cage }(H / D)\end{array}$ & $\begin{array}{l}\text { Bottom Weight/ } \\
\text { Buoyancy Bw/B }\end{array}$ & $\begin{array}{c}\text { Volume Holding } \\
\text { Ratio } C_{V}\end{array}$ & $\begin{array}{c}\text { Equivalent Drag } \\
\text { Coefficient } K_{n}\end{array}$ \\
\hline 1 & 0.09 & 0.63 & 0.39 & 0.93 & 1.12 \\
\hline 2 & 0.09 & 0.70 & 0.20 & 0.78 & 0.95 \\
\hline 3 & 0.09 & 0.56 & 0.14 & 0.71 & 1.00 \\
\hline 4 & 0.09 & 0.28 & 0.29 & 0.83 & 1.56 \\
\hline 5 & 0.09 & 0.35 & 0.45 & 0.92 & 1.45 \\
\hline 6 & 0.09 & 0.49 & 0.33 & 0.89 & 1.21 \\
\hline 7 & 0.12 & 0.28 & 0.14 & 0.63 & 1.35 \\
\hline 8 & 0.12 & 0.35 & 0.33 & 0.68 & 1.45 \\
\hline 9 & 0.12 & 0.70 & 0.29 & 0.61 & 0.95 \\
\hline 10 & 0.12 & 0.49 & 0.39 & 0.86 & 1.16 \\
\hline 11 & 0.12 & 0.56 & 0.20 & 0.74 & 1.00 \\
\hline 12 & 0.12 & 0.63 & 0.45 & 0.90 & 1.07 \\
\hline 13 & 0.15 & 0.49 & 0.29 & 0.72 & 1.06 \\
\hline 14 & 0.15 & 0.56 & 0.45 & 0.84 & 1.07 \\
\hline 15 & 0.15 & 0.35 & 0.39 & 0.81 & 1.27 \\
\hline 16 & 0.15 & 0.63 & 0.14 & 0.77 & 0.87 \\
\hline 17 & 0.15 & 0.70 & 0.33 & 0.79 & 0.92 \\
\hline 18 & 0.15 & 0.28 & 0.20 & 0.68 & 1.34 \\
\hline 19 & 0.18 & 0.70 & 0.45 & 0.78 & 0.94 \\
\hline 20 & 0.18 & 0.28 & 0.33 & 0.71 & 1.36 \\
\hline 21 & 0.18 & 0.63 & 0.29 & 0.73 & 0.91 \\
\hline 22 & 0.18 & 0.56 & 0.39 & 0.75 & 1.01 \\
\hline 23 & 0.18 & 0.49 & 0.20 & 0.66 & 0.98 \\
\hline 24 & 0.18 & 0.35 & 0.14 & 0.64 & 1.12 \\
\hline 25 & 0.21 & 0.35 & 0.20 & 0.62 & 1.12 \\
\hline 26 & 0.21 & 0.49 & 0.45 & 0.76 & 1.05 \\
\hline 27 & 0.21 & 0.28 & 0.39 & 0.72 & 1.35 \\
\hline 28 & 0.21 & 0.70 & 0.14 & 0.88 & 0.80 \\
\hline 29 & 0.21 & 0.63 & 0.33 & 0.72 & 0.90 \\
\hline 30 & 0.21 & 0.56 & 0.29 & 0.68 & 0.95 \\
\hline 31 & 0.24 & 0.56 & 0.33 & 0.71 & 0.94 \\
\hline 32 & 0.24 & 0.63 & 0.20 & 0.77 & 0.85 \\
\hline 33 & 0.24 & 0.49 & 0.14 & 0.71 & 0.93 \\
\hline 34 & 0.24 & 0.35 & 0.29 & 0.51 & 1.12 \\
\hline 35 & 0.24 & 0.28 & 0.45 & 0.74 & 1.34 \\
\hline 36 & 0.24 & 0.70 & 0.39 & 0.80 & 0.87 \\
\hline 37 & 0.09 & 0.35 & 0.29 & 0.68 & 1.59 \\
\hline 38 & 0.12 & 0.35 & 0.29 & 0.63 & 1.43 \\
\hline 39 & 0.15 & 0.35 & 0.29 & 0.61 & 1.29 \\
\hline 40 & 0.18 & 0.35 & 0.29 & 0.58 & 1.21 \\
\hline 41 & 0.21 & 0.35 & 0.29 & 0.53 & 1.16 \\
\hline 42 & 0.12 & 0.28 & 0.29 & 0.71 & 1.63 \\
\hline 43 & 0.12 & 0.43 & 0.29 & 0.76 & 1.26 \\
\hline 44 & 0.12 & 0.49 & 0.29 & 0.70 & 1.17 \\
\hline 45 & 0.12 & 0.56 & 0.29 & 0.61 & 1.09 \\
\hline 46 & 0.12 & 0.63 & 0.29 & 0.63 & 1.01 \\
\hline 47 & 0.12 & 0.35 & 0.14 & 0.53 & 1.30 \\
\hline 48 & 0.12 & 0.35 & 0.17 & 0.54 & 1.33 \\
\hline 49 & 0.12 & 0.35 & 0.20 & 0.55 & 1.35 \\
\hline 50 & 0.12 & 0.35 & 0.24 & 0.59 & 1.52 \\
\hline 51 & 0.12 & 0.35 & 0.30 & 0.69 & 1.56 \\
\hline 52 & 0.12 & 0.35 & 0.36 & 0.67 & 1.60 \\
\hline 53 & 0.12 & 0.35 & 0.39 & 0.71 & 1.48 \\
\hline 54 & 0.12 & 0.35 & 0.42 & 0.72 & 1.46 \\
\hline 55 & 0.12 & 0.35 & 0.45 & 0.72 & 1.50 \\
\hline
\end{tabular}




\section{References}

1. Fisheries Agency. Available online: http://www.jfa.maff.go.jp/j/press/saibai/180330.html (accessed on 2 May 2018).

2. Fu, E.B.; Nashimoto, K.; Yamamoto, K.; Hiraishi, T.; Takagi, T. Model experiment examination of mooring method in aquaculture net cage. Nippon Suisan Gakkaishi 1994, 45, 9-18.

3. Lader, P.F.; Enerhaug, B. Experimental investigation of forces and geometry of a net cage in uniform flow. IEEE J. Ocean. Eng. 2005, 30, 79-84. [CrossRef]

4. Huang, C.C.; Tang, H.J.; Liu, J.Y. Dynamical analysis of net cage structures for marine aquaculture: Numerical simulation and model testing. Aquac. Eng. 2006, 35, 258-270. [CrossRef]

5. Huang, C.C.; Tang, H.J.; Liu, J.Y. Modeling volume deformation in gravity-type cages with distributed bottom weights or a rigid tube-sinker. Aquac. Eng. 2007, 37, 144-157. [CrossRef]

6. Huang, C.C.; Tang, H.J.; Liu, J.Y. Effects of waves and currents on gravity-type cages in the open sea. Aquac. Eng. 2008, 38, 105-116. [CrossRef]

7. Klebert, P.; Patursson, Ø.; Endresen, P.C.; Rundtop, P.; Birkevold, J.; Rasmussen, H.W. Three-dimensional deformation of a large circular flexible sea cage in high currents: Field experiment and modeling. Ocean Eng. 2015, 104, 511-520. [CrossRef]

8. Gansel, L.C.; Oppedal, F.; Birkevold, J.; Tuene, S.A. Drag forces and deformation of aquaculture cages-full-scale towing tests in the field. Aquac. Eng. 2018, 81, 46-56. [CrossRef]

9. Tsukrov, I.; Eroshkin, O.; Fredriksson, D. Finite element modeling of net panels using a consistent net element. Ocean Eng. 2003, 30, 251-270. [CrossRef]

10. Lee, C.W.; Kim, Y.B.; Lee, G.H.; Choe, M.Y.; Lee, M.K.; Koo, K.Y. Dynamic simulation of a fish cage system subjected to current and waves. Ocean Eng. 2008, 35, 1521-1532. [CrossRef]

11. Xu, T.J.; Zhao, Y.P.; Dong, G.H.; Gui, F.K. Analysis of hydrodynamic behavior of a submersible net cage and mooring system in waves and current. Appl. Ocean Res. 2013, 42, 155-167. [CrossRef]

12. Bi, C.W.; Zhao, Y.P.; Dong, G.H.; Zheng, Y.N.; Gui, F.K. A numerical analysis on the hydrodynamic characteristics of net cages using coupled fluid-structure interaction model. Aquac. Eng. 2014, 59, 1-12. [CrossRef]

13. Kristiansen, T.; Faltinsen, O.M. Modelling of current loads on aquaculture net cages. J. Fluids Struct. 2012, 34, 218-235. [CrossRef]

14. Tauti, M. A relation between experiments on model and on full-scale of fishing net. Nippon Suisan Gakkaishi 1934, 3, 171-177. [CrossRef]

15. Hu, F.X.; Shiode, D.; Wan, R.; Tokai, T. Accuracy evaluation of numerical simulation for mid-water trawl nets. In Proceedings of the International Workshop, DEMAT'05, Busan, Korean, 23-26 November 2005; pp. 59-70.

16. Wan, R.; Hu, F.X.; Tokai, T.; Mastuda, K. A method for analyzing the static response of submerged rope systems based on a finite element method. Fish. Sci. 2002, 68, 65-70. [CrossRef]

17. Wan, R.; Hu, F.X.; Tokai, T. A static analysis of the tension and configuration of submerged plane nets. Fish. Sci. 2002, 68, 815-823. [CrossRef]

18. Wan, R.; Huang, W.Q.; Song, X.F.; Hu, F.X.; Tokai, T. Statics of a gillnet placed in a uniform current. Ocean Eng. 2004, 31, 1725-1740. [CrossRef]

19. Hu, F. Studies on the hydrodynamic characteristics and position control of fishing gear. Fish. Eng. 2005, 32, 331-347.

20. Bessonneau, J.S.; Marichal, D. Study of the dynamics of submerged supple nets (applications to trawls). Ocean Eng. 1998, 25, 563-583. [CrossRef]

21. Lee, C.W.; Lee, J.H.; Cha, B.J.; Kim, H.Y.; Lee, J.H. Physical modeling for underwater flexible systems dynamic simulation. Ocean Eng. 2005, 32, 331-347. [CrossRef]

22. Decew, J.; Fredriksson, D.W.; Lader, P.F.; Chambersd, M.; Howelld, W.H.; Osienki, M.; Celikkol, B.; Frank, K.; Høy, E. Field measurements of cage deformation using acoustic sensors. Aquac. Eng. 2013, 57, 114-125. [CrossRef]

23. Bi, C.W.; Zhao, Y.P.; Dong, G.H.; Xu, T.J.; Gui, F.K. Experimental investigation of the reduction in current speed downstream from a fishing net. Aquac. Eng. 2013, 57, 71-81. [CrossRef]

24. Bi, C.W.; Zhao, Y.P.; Dong, G.H.; Xu, T.J.; Gui, F.K. Numerical simulation of the interaction between flow and flexible nets. J. Fluids Struct. 2014, 45, 180-201. [CrossRef] 
25. Dong, S.C.; Hu, F.X.; Kumazawa, T.; Shiode, D.; Tokai, T. Hydrodynamic characteristics of plane netting used for aquaculture net cages in uniform current. Nippon Suisan Gakkaishi 2016, 82, 282-289. [CrossRef]

26. Xu, B.Y.; Zhang, H.J.; Wang, Z.T.; Wang, H.X.; Zhang, Y.L. Model and Algorithm of BP neural network based on expanded multichain quantum optimization. Math. Probl. Eng. 2015, 2015. [CrossRef]

27. Taguchi Designs. Table of Taguchi Designs. University of York Department of Mathematics. Available online: https://www.york.ac.uk/depts/maths/tables/orthogonal.htm (accessed on 16 February 2020).

28. Moe-Føre, H.; Lader, P.F.; Lien, E.; Hopperstad, O.S. Structural response of high solidity net cage models in uniform flow. J. Fluids Struct. 2016, 65, 180-195. [CrossRef]

29. Hu, F.; Matuda, K.; Tokai, T. Effects of drag coefficient of netting for dynamic similarity on model testing of trawl nets. Fish. Sci. 2001, 67, 84-89. [CrossRef]

30. Yamamoto, K.; Mukaida, Y.; Puspito, G.; Hiraishi, T.; Nashimoto, K. A scale effect evaluated by drag measurement comparisons between prototype plane nets and one-fifth model based on tauti's law. Fish. Sci. 1996, 62, 561-565. [CrossRef]

(C) 2020 by the authors. Licensee MDPI, Basel, Switzerland. This article is an open access article distributed under the terms and conditions of the Creative Commons Attribution (CC BY) license (http://creativecommons.org/licenses/by/4.0/). 